\title{
The Effect of University Context on Academics' Engagement with Industry
}

\author{
Zhiyan Zhao*, Zhi Chen \\ ${ }^{1}$ Library, Northwestern Polytechnical University, Xi'an, Shaanxi Province, P.R. China \\ ${ }^{2}$ School of Management, Northwestern Polytechnical University, Xi'an, Shaanxi Province, P.R. China
}

\begin{abstract}
Drawing on the theory of planned behavior, this study investigates the impact of academics' perception of university context on their engagement with industry via the mediation of academics' intention to industrial collaborations. The third mission and supportive policy were put forward as two university influence factors. From analysis results of 564 questionnaire responses, we found that academics' perception of university context had significant effect on academic engagement. In addition, the relationship between university mission, supportive policy and academics' industrial engagement were partially mediated by academics' intention to industrial collaboration.
\end{abstract}

Keywords: University context, The third mission, Supportive policy, Academic engagement.

\section{Introduction}

University knowledge was widely considered as an important source to promote social and economic development. Various interaction types between university and industrial sectors were studied in previous research. Most of them focused on commercialization which refers to transfer of university generated intellectual property. However, academic engagement, containing consulting, joint research, contract research and informal collaborations such as networking and training, has not gotten enough scholarly attention yet, especially in China [1]. Most Chinese universities, like many others in developing countries, are not considered as emerging technology sources by firms in the global scope. Thus, commercial activities in Chinese universities probably does not play same role as western countries. On the contrary, academic engagement may contribute to catch the full picture of academic knowledge diffusion in China.

In order to solve the above problem, the object of this paper is to discover how scientists' perception of their university context will influence their engagement with industry. Based on pervious study constructed under Chinese context $[2,3]$, we put forward the third mission and supportive policy context as two university-level factors. Furthermore, based on theory of planned behavior, we will study mediating mechanism of scientists' intention between the relationship of university context and academic engagement.

* Corresponding author: zhaozhiyan@nwpu.edu.cn 
In the following parts, this present paper begins by hypotheses development. Description of sample collection and methodology is followed in Section 3. Regression results of the hypothesized relationships is presented in Section 4. Discussion, limitation and future research directions are presented in last section.

\section{Hypotheses development}

\subsection{University context and academics' industrial engagement}

Scientists' perception of university context will affect their industrial activities. University's third mission means university takes knowledge transfer as a key objective and as an important aspect [4]. Universities with high third mission usually encourage scientists engage in more applied research. Thus, scientists who perceive their universities stressing third mission, would more likely generate applied research outcome. The mismatch between university's supply and industry's demand will be reduced [5]. Hence, scientists would be more likely engage in industrial activities.

Previous studies have found that university's incentive policy, such as sophisticated TTO (technology transfer office) functions, the distribution of benefits between scientists, university and industry sectors and promotion process, promote scientists' industrial activities [6,7]. Sophisticated TTO (technology transfer office) functions could strengthen scientists' advantage to search external collaboration with industry partners in a competitive environment. Incentives could stimulate scientists to engage in industry collaborations for commercial benefits or career development. Based on the above analysis, we put forward the following hypotheses:

H1a: Scientists' perception of university third mission is positively related to their industrial engagement.

H1b: scientists' perception of university supportive policy is positively related to their industrial engagement.

\subsection{University context and scientists' intention to industrial engagement}

University context could positively affect scientists' intention to industrial collaborations by enhancing their ability and confidence in university-industry interactions. Scientists in universities stressing the third mission would have advantage in applied value research outcome. University incentives could increase scientists' intention to collaborate with industry for commercial benefits or promotion. Sophisticated TTO service could enhance scientists' ability to finish contracts from industrial partners. Thus, both university third mission and supportive policy context probably improve scientists' intention to industrial activities. We put forward following hypotheses:

H2a: Scientists' perception of university third mission is positively related to their intention to industrial engagement.

$\mathrm{H} 2 \mathrm{~b}$ : Scientists' perception of university supportive policy is positively related to their intention to industrial engagement.

\subsection{The mediating effect of scientists' engagement intention}

The theory of planned behavior provides the mechanism of relationship between intention and individual's behavior. As the theory of planned behavior, intention is the internal reason that leads to one's behavior [8]. This is because intention is a signal indicating how much one is willing to try and make efforts for an object. A strong intention will result in high 
possibility of behavior occurrence. Scientists' intention to industrial activities represent for their willingness to academic engagement. It reflects scientists' acceptance to industrial collaborations. The stronger intention scientists hold, the more likely they would engage in industrial activities. Thus, we put forward the following hypotheses:

H3: Scientists' intention to industrial engagement has a positive impact on academic engagement.

Combining the above analysis, we could conclude that supportive university context would enhance scientists' intention to engage in industrial collaborations. Scientists' intention will result in more practice in industry by willingness and efforts. Thus, we put forward the following hypothesis:

H4: The relationship between university context and academic engagement is mediated by scientists' intention to industrial engagement.

\section{Methodology}

\subsection{Sample}

Respondents of this study are scientists from Chinese universities. Most of data was collected through email addresses which were searched from universities' official website. Small part was collected through paper questionnaire and mobile tools. To ensure response rate, data collection was conducted in two stages. First, a pilot investigation in a group of 50 scientists was conducted via email which aimed to consult scientists' suggestion of questionnaire. Second, extensive survey was initiated through scientists' email addresses. A reminder mail was sent to respondents who did not reply in one week. Finally, 564 complete data were collected in the final sample. Result of T-test show that early and late returned data have no significant differences in terms of gender, number of publication, rank and industrial connection, suggesting that non-response bias was not problem in our sample.

\subsection{Measures}

\subsubsection{Dependent variable}

We used two methods to measure scientists", engagement with industry by experience of previous study [9]. The first way was to construct academic engagement index by frequencies (above 10 times; 6-9; 3-5 times; $1-2$ times; and 0 times) of scientists in 11 types of industrial activities in 2014 and 2015 (see table 1). Academic engagement index was computed through several processes. Difficulty degree of each type of activity was firstly computed: $d_{j}=1-$ $\frac{\sum_{n=1}^{N} b_{n, j}}{N}$, where $j=1 \cdots 11$ was type of activity; $N=564$ was the size of our sample; $b_{n, j}$ equaled to 1 if the $n$th scientist engaged in $j$ th activity, otherwise 0 . Second, academic engagement index was computed: $E_{n}=\sum_{j=1}^{11} d_{j} T_{j}$, where $T_{j}$ was the averages of each frequency interval which were $0,1.5,4,7.5$ and 10 respectively. Another measurement of academic engagement aimed to check the robustness of our main result, and was calculated by the number of types scientists engaged in 11 activities. 
Table 1. Scientists' industrial engagement activities and difficulty degree.

\begin{tabular}{lc}
\hline $\begin{array}{l}\text { How Frequently Have You Been Engaged in the Following Types of Activities } \\
\text { in 2014 and 2015? }\end{array}$ & $\begin{array}{c}\text { Difficulty } \\
\text { Degree }\end{array}$ \\
\hline 1. A new joint research agreement sponsored by industry (original research & 0.213 \\
$\quad$ work undertaken by both partners) & 0.436 \\
2. A new joint research agreement sponsored by a third party (original research & 0.628 \\
$\quad$ work undertaken by both partners) & 0.298 \\
3. Work with industry personnel that resulted in a patent or copyright & 0.543 \\
4. A new consultancy agreement (no original research undertaken) & 0.498 \\
5. Secondment to industry (short- or long-term) & 0.417 \\
6. Training of company employees (through course enrollment or temporary & 0.418 \\
7. Personnel exchanges) & 0.640 \\
8. A new contract research agreement (original research work done by the & 0.324 \\
$\quad$ University alone) & 0.427 \\
9. Creation of new physical facilities with industry funding (e.g., new & laboratory, other building on campus) \\
10. Attendance at conferences with industry and university participation & 11. Attendance at industry-sponsored meetings \\
\hline
\end{tabular}

\subsubsection{Independent, mediating and control variables}

Independent variables of this study are the third mission and supportive policy context. The scale of third mission was adapted from Guerrero and Urbano [4] and was measured by five items. The scale of supportive was adapted from $\mathrm{Wu}$ [2] and was also measured by five questions. Scientists' intention to academic engagement was measured by asking them how likely they would engage in each kind of industrial activities in future.

In addition, this study controlled for several variables that may have confounding effects on academic engagement. A dummy variable was utilized to measure gender $(0=$ female, $1=$ male). Master and doctoral supervisor were measured by dummy variables, in which master or doctoral supervisor was coded 1 and otherwise was coded 0 . Publication and public funds were measured by the number of respondents' publication and public funds in 2014 and 2015. A dummy variable was used to measure academic rank ( $1=$ professor or associate professor; $0=$ lecturer or assistant). We used a dummy variable to measure industrial connection, in which having a secondary position in industrial departments was coded 1 and otherwise was coded 0 . Scientists' previous experience in industrial engagement was scaled by a Likert five-point scale in which 1-5 denoted from totally disagree to totally agree.

\subsection{Descriptive statistics results and empirical evaluation of measurements}

Descriptive statistics results and correlation matrix of all variables is presented in Table 2. Reliability and validity of measurements were checked. Results of reliability analysis showed that Cronbach's of the third mission, supportive policy and intention were $0.826,0.835$ and 0.955 respectively, indicating the reliability of measurements. Exploratory factor analysis showed that KMO was 0.887 and the significance of Bartlett's test was 0.000 , suggesting that it was suitable for factor analysis. The minimum standardized factor loading was over 0.5. Thus, validity of measurements was confirmed. 
Table 2. Descriptive statistics results and correlations matrix $(\mathrm{N}=564)$.

\begin{tabular}{|c|c|c|c|c|c|c|c|c|c|c|c|c|c|}
\hline \multirow{2}{*}{ Variables } & \multicolumn{13}{|c|}{ Correlation Matrix } \\
\hline & (1) & (2) & (3) & (4) & (5) & (6) & (7) & $(8)$ & (9) & (10) & (11) & (12) & (13) \\
\hline (1) Gender & 1.00 & & & & & & & & & & & & \\
\hline $\begin{array}{l}\text { (2) Master } \\
\text { supervisor }\end{array}$ & 0.14 & 1.00 & & & & & & & & & & & \\
\hline $\begin{array}{l}\text { (3) Doctoral } \\
\text { supervisor }\end{array}$ & 0.05 & 0.45 & 1.00 & & & & & & & & & & \\
\hline (4) Publication & 0.08 & 0.24 & 0.37 & 1.00 & & & & & & & & & \\
\hline (5) Public funds & 0.13 & 0.30 & 0.28 & 0.45 & 1.00 & & & & & & & & \\
\hline (6) Rank & 0.22 & 0.42 & 0.39 & 0.24 & 0.31 & 1.00 & & & & & & & \\
\hline $\begin{array}{l}\text { (7) Industrial } \\
\text { connection }\end{array}$ & 0.14 & $-\overline{0.03}$ & 0.08 & 0.14 & 0.14 & 0.03 & 1.00 & & & & & & \\
\hline (8) Experience & 0.03 & 0.06 & 0.09 & 0.14 & 0.07 & 0.10 & 0.22 & 1.00 & & & & & \\
\hline (9) Third mission & 0.11 & 0.17 & 0.12 & 0.14 & 0.20 & 0.22 & 0.13 & $\begin{array}{l}- \\
0.10\end{array}$ & 1.00 & & & & \\
\hline $\begin{array}{l}\text { (10) Supportive } \\
\text { policy }\end{array}$ & 0.06 & 0.15 & 0.11 & 0.10 & 0.14 & 0.20 & 0.10 & 0.01 & 0.32 & 1.00 & & & \\
\hline (11) Intention & 0.17 & 0.25 & 0.19 & 0.24 & 0.26 & 0.36 & 0.22 & 0.20 & 0.43 & 0.40 & 1.00 & & \\
\hline $\begin{array}{l}\text { (12) Academic } \\
\text { engagement } \\
\text { index }\end{array}$ & 0.22 & 0.29 & 0.28 & 0.31 & 0.32 & 0.36 & 0.31 & 0.18 & 0.43 & 0.36 & 0.47 & 1.00 & \\
\hline $\begin{array}{l}\text { (13) Academic } \\
\text { engagement II }\end{array}$ & 0.26 & 0.32 & 0.28 & 0.32 & 0.39 & 0.53 & 0.24 & 0.14 & 0.51 & 0.36 & 0.56 & 0.81 & 1.00 \\
\hline Mean & 0.62 & 0.52 & 0.19 & 6.34 & 1.38 & 0.56 & 0.24 & 3.17 & $\begin{array}{c}11.3 \\
5\end{array}$ & $\begin{array}{c}10.4 \\
8\end{array}$ & $\begin{array}{c}11.9 \\
7\end{array}$ & 8.59 & 6.16 \\
\hline $\begin{array}{l}\text { Standard } \\
\text { Deviation }\end{array}$ & 0.49 & 0.50 & 0.39 & 5.52 & 1.24 & 0.50 & 0.43 & 1.05 & 2.77 & 2.97 & 4.08 & 8.33 & 3.88 \\
\hline
\end{tabular}

\section{Results}

Hierarchical regression analysis was used for hypotheses testing. Results were presented in table 3. Model 1 presents effects of control variables on intention. University level factors were added in model 2 to test the effects of third mission and supportive policy on intention. Coefficients were positive and significant indicating that $\mathrm{H} 2 \mathrm{a}$ and $\mathrm{H} 2 \mathrm{~b}$ were confirmed. Model 3 was to confirm the effect of control variables on academic engagement index. In model 4, university factors were added and results showed that $\mathrm{H} 1 \mathrm{a}$ and $\mathrm{H} 1 \mathrm{~b}$ were supported. Model 5 was set to test the effect of scientists' intention on their industrial engagement behaviors and results showed that $\mathrm{H} 3$ was supported. Both control variables, mediating and university level factors were put in model 6 . Results showed that intention had a partly mediating effect between relationship of university context and academic engagement. Thus, H4 was supported.

Table 3. Hierarchical regression analysis results $(\mathrm{N}=564)$.

\begin{tabular}{lllllll}
\hline \multirow{2}{*}{ Variables } & intention & \multicolumn{5}{c}{ academic engagement index } \\
\cline { 2 - 7 } & Model 1 & Model 2 & \multicolumn{1}{l}{ Model 3 } & Model 4 & Model 5 & Model 6 \\
\hline \multirow{2}{*}{ Gender } & 0.536 & 0.447 & $1.794^{* *}$ & $1.616^{* *}$ & $1.478^{*}$ & $1.493^{* *}$ \\
& $(0.327)$ & $(0.291)$ & $(0.634)$ & $(0.577)$ & $(0.606)$ & $(0.573)$ \\
Master & $0.843^{*}$ & 0.486 & $1.928^{* *}$ & $1.291^{*}$ & $1.430^{*}$ & 1.157 \\
supervisor & $(0.366)$ & $(0.327)$ & $(0.709)$ & $(0.647)$ & $(0.680)$ & $(0.643)$ \\
Doctoral & -0.372 & -0.281 & 1.217 & 1.386 & 1.436 & 1.464 \\
supervisor & $(0.470)$ & $(0.419)$ & $(0.913)$ & $(0.830)$ & $(0.871)$ & $(0.823)$ \\
Publication & $0.065^{*}$ & 0.054 & $0.178^{* *}$ & $0.156^{* *}$ & $0.140^{*}$ & $0.142^{*}$ \\
\hline
\end{tabular}




\begin{tabular}{|c|c|c|c|c|c|c|}
\hline & $(0.033)$ & $(0.029)$ & $(0.063)$ & $(0.057)$ & $(0.060)$ & $(0.057)$ \\
\hline & 0.269 & 0.126 & $0.727^{*}$ & 0.466 & $0.568^{*}$ & 0.431 \\
\hline Public funds & $(0.144)$ & $(0.129)$ & $(0.280)$ & $(0.255)$ & $(0.268)$ & $(0.253)$ \\
\hline Donk & $2.052^{* * * *}$ & $1.401^{* * *}$ & $3.152^{* * *}$ & $1.989^{* *}$ & $1.940^{* *}$ & $1.603^{*}$ \\
\hline Rank & $(0.362)$ & $(0.327)$ & $(0.703)$ & $(0.647)$ & $(0.689)$ & $(0.652)$ \\
\hline Industrial & $1.546^{* * *}$ & $0.947^{* *}$ & $4.619^{* * *}$ & $3.527^{* * *}$ & $3.706^{* * *}$ & $3.266^{* * *}$ \\
\hline connection & $(0.379)$ & $(0.341)$ & $(0.735)$ & $(0.675)$ & $(0.711)$ & $(0.674)$ \\
\hline Fxnerience & $0.456^{* *}$ & $0.670^{* * * *}$ & $0.578^{*}$ & $0.991^{* * *}$ & 0.309 & $0.806^{* *}$ \\
\hline Experience & $(0.150)$ & $(0.136)$ & $(0.291)$ & $(0.268)$ & $(0.280)$ & $(0.272)$ \\
\hline $\begin{array}{l}\text { Third } \\
\text { mission }\end{array}$ & & $\begin{array}{l}0.418^{* * * *} \\
(0.054)\end{array}$ & & $\begin{array}{l}0.833^{* * *} \\
(0.107)\end{array}$ & & $\begin{array}{l}0.717^{* * *} \\
(0.112)\end{array}$ \\
\hline $\begin{array}{l}\text { Supportive } \\
\text { policy }\end{array}$ & & $\begin{array}{l}0.337^{* * *} \\
(0.049)\end{array}$ & & $\begin{array}{l}0.513^{* * *} \\
(0.097)\end{array}$ & & $\begin{array}{l}0.420^{* * *} \\
(0.100)\end{array}$ \\
\hline Intention & & & & & $\begin{array}{l}0.590^{* * *} \\
(0.079)\end{array}$ & $\begin{array}{l}0.276^{* *} \\
(0.083)\end{array}$ \\
\hline Constant & $\begin{array}{l}7.518^{* * *} \\
(0.545)\end{array}$ & $\begin{array}{l}-0.423 \\
(0.820)\end{array}$ & $\begin{array}{l}-0.594 \\
(1.057)\end{array}$ & $\begin{array}{l}-14.897^{* * *} \\
(1.623)\end{array}$ & $\begin{array}{l}-5.033^{* * *} \\
(1.168)\end{array}$ & $\begin{array}{l}-14.780^{* * *} \\
(1.609)\end{array}$ \\
\hline Adjusted $R^{2}$ & 0.210 & 0.373 & 0.287 & 0.412 & 0.352 & 0.422 \\
\hline$\triangle R^{2}$ & 0.210 & 0.163 & 0.287 & 0.125 & 0.065 & 0.135 \\
\hline
\end{tabular}

Note: $* \mathrm{p}<0.05, * * \mathrm{p}<0.01, * * * \mathrm{p}<0.001$.

In order to test robustness of this study, we used second measurement of academic engagement to substitute academic engagement index in model 3-6. Poisson regression run by Stata 13 showed that main results remained. Thus, robustness was confirmed.

\section{Discussion, limitation and future research directions}

Taking Chinese scientists as sample group, this study drew on the theory of planned behavior and used hierarchical regression analysis to study the effect of organizational factors on academic engagement. Our analysis results found that perception of university third mission and supportive policy have significant effect on scientists' engagement with industry. Scientists' intention to industrial activities has a partly mediation role between the relationship of university context and academic engagement.

Theoretical contribution of this study lies in three aspects. First, our research constructed under Chinese context and university-level factors were put forward by analysis of Chinese context. Thus, we bring a novel insight of university-industry interactions in Chinese universities. Second, we broaden extant research of university-industry interactions in China. Previous research mainly focused on commercialization and few concern non-commercial and informal interactions between university and industry. Our research provides a full picture of Chinese university knowledge diffusion. Third, we revealed the mechanism of the impact of scientists' perception of external context on their industrial behavior.

Our study also has practical contributions. Manager and policy-maker should not only focus on formulating relevant policies, but also should concern how scientists perceive external context. Because it is also important to predict their behavior. In addition, scientists' intention plays a mediation role between university context and academic engagement, so managers could promote scientists to engage in academic knowledge diffusion by enhancing their intention to industrial collaborations.

Limitation of this study also indicates directions for future research. Scientists in some department such as art and language refuse to response our survey for the reason that they did not have industrial activities. Future research could utilize secondary data to analyze academics' industrial activities. 


\section{Acknowledgements}

This research was financially supported by the Fundamental Research Funds for the Central Universities (3102020JC02) and Development Strategy Research Funds of Northwestern Polytechnical University.

\section{References}

1. M. Perkmann,V. Tartari, M. Mckelvey, et al. Research Policy, 42(2), 423-442, (2013).

2. W. Wu. The Journal of Technology Transfer, 35(2), 203-224, (2010)

3. W. Wu, Y. Zhou. The Journal of Technology Transfer, 37(6), 812-827, (2012)

4. M. Guerrero, D. Urbano. The Journal of Technology Transfer, 37(1), 43-74, (2012)

5. H. Lööf, A. Broström. The Journal of Technology Transfer, 33(1), 73-90, (2008)

6. R. P. O'shea, T. J. Allen, K. P. Morse, et al. R\&D Management, 37(1), 1-16, (2007)

7. R. P. O'shea, H. Chugh, T. J. Allen. The Journal of Technology Transfer, 33(6), 653666, (2008)

8. I. Ajzen. Organizational behavior and human decision processes, 50(2), 179-211, (1991)

9. B. Bozeman, M. Gaughan. Research Policy, 36(5), 694-707, (2007) 